\title{
ENVIRONMENTAL EDUCATION TO BOOST PRO-ENVIRONMENTAL BEHAVIOUR IN REDUCING PLASTICS CONSUMPTION AMONG STUDENTS IN UNIVERSITAS BINA DARMA PALEMBANG
}

\author{
Risqo M. Wahid ${ }^{1}$ \\ ${ }^{1}$ Lecturer, \\ Faculty of Economics, \\ Universitas Indo Global Mandiri, \\ Palembang, \\ Indonesia
}

\author{
Endah Dewi Purnamasari ${ }^{2}$ \\ ${ }^{2}$ Assistant Professor, \\ Faculty of Economics, \\ Universitas Indo Global Mandiri, \\ Palembang, \\ Indonesia
}

\author{
Fitriya Fauzi ${ }^{3}$ \\ ${ }^{3}$ Assistant Professor, \\ Faculty of Economics and Business, \\ Universitas Muhammadiyah Palembang, \\ Palembang, Indonesia
}

Article DOI: $\underline{\text { https://doi.org/10.36713/epra4913 }}$

\begin{abstract}
This study investigates university students' perception, attitude, and self-reported pro-environmental behaviour concerning plastic consumption and pollution pre- and post-environmental education (EE). There were 161 students participating in the EE and completing questionnaires. These data were collected from the students of Universitas Bina Darma in Palembang, Indonesia. The analysis process employed Wilcoxon sign-rank tests. The findings exhibit that students perception, attitude, and self-reported pro-environmental behaviour regarding plastic consumption and pollution significantly increased after the implementation of environmental education. This study can benefit universities, governments, and non-governmental bodies for policymaking and other environmental decisions to reduce plastic consumption and pollution for more sustainable future.
\end{abstract}

KEYWORDS: Plastic Pollution, Indonesia, Sustainability, Environmental Education, Ethical Consumption

\section{INTRODUCTION}

Plastic pollution is detrimental to the environment, economy, social, and human health (Xanthos and Walker, 2017). Implementation of environmental education (EE), which includes education on plastic consumption, could reduce this problem (Auta, Emenike and Fauziah, 2017; Ogunola, Onada and Falaye, 2018). Notably, environmental education can increase consumer knowledge and awareness, which can potentially change consumer behaviour to be more environmentally responsible (Raman Sharma and Sharma, 2014; Ma'ruf, Surya and Apriliany, 2016). The recommended group to be the primary target of implementing this strategy are young consumers (e.g., high school and college students) (Hartley, Thompson and Pahl, 2015; Ma'ruf, Surya and Apriliany, 2016). These demographics are future educated workers, company leaders, policymakers, and government leaders (Hammami et al., 2017; Parker, Prabawa-Sear and Kustiningsih, 2018). Their essential roles as decision-makers can influence long-term sustainability and environmental health (Kong et al., 2014; Ergen, Baykan and Turan, 2015).

This implementation of EE toward young consumers is substantially urgent for Indonesia (Parker, 2018; Parker, Prabawa-Sear and Kustiningsih, 2018; Prabawa-Sear, 2018; Tanu and Parker, 2018). The country is the second-largest plastics polluter after China (Jambeck et al., 2015; 
Ritchie and Roser, 2018), producing 3.2 million metric tons of mismanaged plastic waste (McCarthy, 2020), and having four of the most polluted rivers in the world (Lebreton et al., 2017). Also, Parker et al. (2018) revealed that young consumers in Indonesia are unaware that consumerist culture contributes to the environmental degradation, generally acceptable to use plastic bags, and always throwing litters on the ground if bins are absent.

Several studies have investigated the efficacy of $\mathrm{EE}$ in Indonesia. In ethnographic research, Prabawa-Sear (2018) uncovered that senior high school students in Yogyakarta and Surabaya are more motivated to win the environmental prestige, prizes, and competitions rather than learning about the environment. In another ethnographic examination, Tanu and Parker (2018) found that high school students in Surabaya join environmental programmes for a feeling of belonging to a group. This indicates that the actual environmental education contents are unnecessary. The findings of both studies show that $\mathrm{EE}$ in Indonesia remains unsatisfactory (Parker, 2018), and hence there is still a need to assess other EE methodology using different sets of participants. In addition, in their exploratory analysis on university students in three different main islands (i.e., Sumatra, Java, and Bali), Ma'ruf et al. (2016) evidenced that environmental knowledge affects environmental attitude, and attitude affects environmental behaviour intention. Although the effort is beneficial, this latter study merely confirms the relationships among the variables. Further study should extend this attempt by testing an $\mathrm{EE}$ in university classes and measuring its efficacy.

To address the lacunae mentioned above, this study provided EE to students in Universitas Bina Darma in Palembang in an attempt to boost proenvironmental behaviour in reducing plastic consumption. To measure the success or failure of the EE intervention, this study investigated the students' perception, attitudes, and proenvironmental behaviour concerning plastic consumption and pollution. These measurements were conducted during pre- and post-intervention. This research offers three contributions to EE literature. First, this empirical analysis expands the ethnographic studies among high school students conducted by Prabawa-Sear (2018) and Tanu and Parker (2018). Second, $73 \%$ of EE studies are from developed countries in North America and Europe (Varela-Losada et al., 2016). Thus, this research enriches the EE literature in developing countries, especially on the issue of plastics consumption in Indonesia. Third, Ma'ruf et al. (2016) have proven that knowledge, environmental attitude, regulatory attitude, and environmental behaviour differ significantly among their respondents in Sumatra,
Java, and Bali islands. This occurs because Indonesia is a nation with a vast territory, cultural diversity, and distinct environmental problems encountered by each region (Ma'ruf, Surya and Apriliany, 2016). Therefore, the analysis in Palembang in this study provides new evidence for the EE in Indonesia. From the practical standpoint, the applied EE and results of this study can benefit universities, governments, and non-governmental bodies for policymaking and other environmental decisions to reduce plastics consumption and pollution for more sustainable future.

\section{LITERATURE REVIEW 2.1. Causes and Effects of Plastics Pollution}

Based on the research by Geyer et al. (2017), in 2015, plastic waste in the packaging forms in the world reached 141 million tons. They also predicted that by 2050 , plastic production will attain 34 billion tons, and 12 billion tons of this figure will accumulate into plastic waste. Consumers purchasing products with unnecessary plastic packaging cultivate this inordinate problem (Ohtomo and Ohnuma, 2014; Rivers, ShenstoneHarris and Young, 2017; Xanthos and Walker, 2017). This situation is further exacerbated by the sizeable number of people littering plastics (Barboza and Gimenez, 2015; Kiessling et al., 2017), where the insufficient presence of litter bins is considered to be one of the causes (Hartley, Thompson and Pahl, 2015).

Plastic pollution adversely affects multifarious aspects surrounding human lives. First, it aggravates the tourism industry. For example, Hawaii and Maldives experience declining tourists due to plastic waste bestrewing their beaches (Ogunola, Onada and Falaye, 2018). In addition, plastic pollution decreases fish populations in the sea, reducing the income of the fisheries sector (Ogunola, Onada and Falaye, 2018). On a global scale, plastic pollution weakens the economy, causing estimated annual losses as much as $\$ 13.3$ billion (Ogunola, Onada and Falaye, 2018). From the environmental stance, plastic pollution deteriorates the marine ecosystem (da Costa et al., 2016; Auta, Emenike and Fauziah, 2017; Geyer, Jambeck and Law, 2017). Lastly, because plastics parse and spread through the biosphere, including air, water, and soil, plastic pollution worsens the quality of these elements (da Costa et al., 2016; Geyer, Jambeck and Law, 2017). This subsequently has the potential to damage human organs (e.g., lungs, liver, brain, and skin) and also to prompt cancer (Vethaak and Leslie, 2016; Hammami et al., 2017).

Plastics are high in durability, and they need between 100 to 1,000 years for degradation (Wang et al., 2016). To ensure sustainability in the future, 
consumers must change their consumption behaviour (Ohtomo and Ohnuma, 2014; Hasan, Harun and Hock, 2015; Hammami et al., 2017). This can be done by inviting others to be more proenvironment, throwing rubbish in its place, and reducing plastic usage (Hartley, Thompson and Pahl, 2015).

\subsection{The Effects of EE on Perception, Attitude, and Pro-Environmental Behaviour}

In their ethnographic studies, Tanu \& Parker (2018) and Prabawa-Sear (2018) evidenced that the implemented EE failed to enhance environmental knowledge. These studies argue that insufficient EE contents cause failure. Tanu \& Parker (2018) revealed that high school students in Surabaya participate in environmental activities only to belong in a group. This occurs because the EE provider focuses their contents more on 'togetherness of family' rather than the EE contents. Almost identical, Prabawa-Sear (2018) proved that high school students in Yogyakarta and Surabaya conduct pro-environmental behaviour merely to win the prestige, prizes, and competitions held by environmental bodies in their cities. The EE model encourages students and schools more to compete rather than to learn about the environment and how to sustain it.

Outside of Indonesia, a quasi-experimental design in a public high school in Israel (Gottlieb, Vigoda-Gadot and Haim, 2013) found that EE positively affects pro-environmental behaviour intention but fail to improve the self-reported proenvironmental behaviour among students. This investigation postulates that the experimental EE was effective. The lack of improvement in actual pro-environmental behaviour might not be caused by the implemented EE but by the accessibility of litter bins in the school, products sold in the cafeteria, or prices.

Other studies also provided favourable outcomes. Sipone, Abella-García, Barreda, \& Rojo (2019) prove that through EE, Spanish students (aged 10 to 12 ) obtain new environmental knowledge that potentially leads to increased proenvironmental behaviour. More extensively, Hartley et al. (2015) showed that after the implementation of $\mathrm{EE}$, the perception, attitude, and pro-environmental behaviour of English students (aged 8 to 13) improved significantly. In a university level, in their study of Indonesian students, Ma'ruf et al. (2016) evidenced that environmental knowledge affects environmental attitude, and attitude affects environmental behaviour intention. This indicates that the provision of EE for university students might improve their perception, attitude, and proenvironmental behaviour.

This study attempts to provide EE to Indonesian university students. Unlike the EE as examined by Tanu \& Parker (2018) and PrabawaSear (2018), this study implemented EE with neither 'togetherness' activities nor rewards. Therefore, based on preliminary findings (Gottlieb, VigodaGadot and Haim, 2013; Hartley, Thompson and Pahl, 2015; Sipone et al., 2019), this study predicts students' perception, attitude, and pro-environmental behaviour will improve after participating in EE classes.

\section{METHODOLOGY \\ 3.1 Design}

In data collection, this study formulated the questionnaires based on preliminary studies of Hartley et al. (2015) and Hammami et al. (2017). The researchers translated the questionnaires from English to Indonesian. A pilot study then was conducted on a sample of 20 subjects to test the suitability of the questions on Indonesian students. After some reviews, the researchers conducted several modifications and wrote the questionnaires on Google Form. The final measurements of the survey were presented as follows.

\subsubsection{Perception}

The perceived amount of plastic waste in the world and estimated degradation time. In this context, this research asked, "How much is plastic waste in the world?" This study provided an open answer and guided the students to use weight scales (e.g., gram, kilograms, or tons). Also, the study further queried, "How long do you think it takes for plastics to decompose?" Following Hartley et al. (2015), this study arranged an open response with no provision of timescales (e.g., seconds, minutes, days, months, or years).

Perceived causes. This study inquired 3 questions to measure the students' perception of the causes of plastic pollution. The questions are, "What does cause plastic pollution: (a) the insufficiency of litter bins; (b) the products we purchase use too much plastic packaging; (c) too many people litter in the environment?" Participants could respond either with strongly disagree $=1$; disagree $=2$; agree $=3$; or strongly agree $=4$

Perceived negative impacts. For the perception of plastic pollution adverse effects, this study questioned the students with, "Do you think plastic pollution is bad for: (a) marine wildlife; (b) tourism industry; (c) fishery industry; (d) quality of air; (e) quality of water; (f) quality of soil; (g) humans' hearts; (h) humans' skins; (i) humans' lungs; (j) humans' brains?" Participants could respond either with strongly disagree $=1$; disagree $=2$; agree $=3$; or strongly agree $=4$. 


\subsubsection{Attitude}

For measurement of attitude toward plastic consumption and pollution, this study presented a statement, "I am willing to spread awareness about the causes and effects of plastic pollution to my friends and family." Participants could respond either with strongly disagree $=1 ;$ disagree $=2$; agree $=3$; or strongly agree $=4$.

\subsubsection{Pro-Environmental Behaviour}

This study asked self-reported proenvironmental behaviour to examine the participants' pro-environmental behaviour. The queries for this investigation are: "Within the last 7 days, have you done the following things: (a) brought own bags for shopping; (b) reduced the usage of single-use plastics; (c) reduced purchasing on food and beverage that use plastic packaging?" Participants could respond either with not at all $=1 ; a$ little bit $=2$; quite a bit $=3$; or a lot $=4$.

\subsubsection{Additional Questions}

In the questionnaires after the $\mathrm{EE}$ intervention, this study further asked 2 questions that might inform future studies and both government and non-governmental bodies. First, this investigation inquired the students, "Do you intend to join more formal environmental education in the future?" The students could choose between "Yes, I do" and "No, I don't". Second, this research explored the best media to deliver EE, according to university students. The question was, "What media do you think are the most effective to deliver environmental education?" The answers for the question were: (a) formal class in a school/university; (b) Instagram; (c) Facebook; (d) Snapchat; (e) Twitter; (f) YouTube; (g) TV; (h) radio; (i) newspaper; (j) blog; (k) other. The participants could tick more than one answer. For the option (k) other, it was an open response. Students could propose a new medium other than those listed in the options.

\subsection{Participants}

The participants of this repeated measures design were university students from Universitas Bina Darma in Palembang, Indonesia. The researchers visited 6 classes with the total average students of 30 . Before the delivery of EE, the researchers forwarded the link of the Google Form containing questionnaires to one of the students in the classes. He or she then shared the link to his or her class WhatsApp groups. The researchers emphasised that only the students attending the classes at that time of EE delivery were allowed to fill the questionnaires. The participants mostly finished filling the questionnaires within 5 minutes. After 7 days of the EE, the researchers revisited the same classes and distributed the after EE intervention questionnaires. Similar to the previous process, students completed the questionnaires in 5 minutes. The total data from before and after the EE intervention were 190 and 177, respectively. Due to double entry by the students and missing values, the final data decreased to 161 .

Table 1: Demographics of Participants

\begin{tabular}{|l|c|c|}
\hline & $\mathbf{n}$ & $\mathbf{\%}$ \\
\hline Residence: & & \\
\hline Urban & 109 & 67.7 \\
\hline Suburban & 26 & 16.1 \\
\hline Rural & 26 & 16.1 \\
\hline Gender: & & \\
\hline Male & 50 & 31.1 \\
\hline Female & 111 & 68.9 \\
\hline Have you ever participated in at least one formal EE class before? & & \\
\hline Yes, I have & 105 & 65.2 \\
\hline Never & 56 & 34.8 \\
\hline Age: & & \\
\hline 17 & 11 & 6.8 \\
\hline 18 & 47 & 29.2 \\
\hline 19 & 57 & 35.4 \\
\hline 20 & 35 & 21.7 \\
\hline 21 & 9 & 5.6 \\
\hline 22 & 1 & 0.6 \\
\hline 23 & 1 & 0.6 \\
\hline & & \\
\hline Age & Mean & SD \\
\hline
\end{tabular}


The characteristics of the participants are tabulated in Table 1. Most of the students lived in an urban area $(\mathrm{n}=109)$, then followed equally by suburban and rural (both $\mathrm{n}=26$ ). A total of 111 participants were female, and 50 of them were male. Majority of them have joined at least one formal EE class before $(n=105)$, and the rest of them were never $(\mathrm{n}=56)$. The average age was $18.95(\mathrm{SD}=1.11)$, and this criterion was dominated by the age of $18(n=47)$, $19(\mathrm{n}=57)$, and $20(\mathrm{n}=35)$.

\subsection{Intervention}

The researchers visited ongoing classes and asked permission from the respective lecturers to take approximately 20 minutes to conduct $\mathrm{EE}$ in their classes. Once allowed, the process began by distributing questionnaires. After this, the researchers educated the university students about plastic pollution. The style of teaching was formal and using the Indonesian language. The tools used were slideshows with no other extra instruments (e.g., microscopes). The total slides were 6 explaining: (1) total plastic waste in the world (Geyer, Jambeck and Law, 2017); (2) plastic decomposing time (Wang et al., 2016); (3) cause of plastics pollution (Ohtomo and Ohnuma, 2014; Barboza and Gimenez, 2015; Hartley, Thompson and Pahl, 2015; Kiessling et al., 2017; Rivers, Shenstone-Harris and Young, 2017; Xanthos and Walker, 2017); (4) effects of plastics pollution to the marine ecosystem and tourism and fishery industries (Ogunola, Onada and Falaye, 2018); (5) effects of plastics pollution to the quality of air, water, and soil (da Costa et al., 2016; Geyer, Jambeck and Law, 2017); (6) effects of plastics pollution to humans' health (Vethaak and Leslie, 2016; Hammami et al., 2017). Along with texts in the slides, the researchers also presented relevant pictures to illustrate the dire problems caused by plastic pollution.

\subsection{Statistical Analysis}

The dependent variables of this study were: (a) perceived amount of plastic waste in the world and estimated degradation time; (b) perceived causes; (c) perceived negative impacts; (d) attitude; and (e) self-reported pro-environmental behaviour. This study implemented non-parametric statistical methods considering the majority of the data were ordinal (1-4 response scale). Following previous research (Hartley, Thompson and Pahl, 2015), this study checked the difference items mean during each of the pre- and post-intervention using the Friedman test. This process was explicitly for the variables of perceived causes, perceived negative impacts, and self-reported pro-environmental behaviour. If the items within each category were significantly different, the analysis continued to post hoc Wilcoxon matched-pair tests. Lastly, this investigation applied Wilcoxon's matched-pairs signed-ranks ( $Z$ score) to determine whether EE intervention influenced students' perception (i.e., the perceived proportion of plastic waste in the world and estimated degradation time; perceived causes; and perceived impacts), attitude, and self-reported pro-environmental behaviour.

\section{RESULTS}

\subsection{Perception of Plastics Pollution}

The perceived amount of plastic waste in the world and estimated degradation time

Before the EE intervention, students believed the average amount of plastic waste in the world was merely 22.176 million tons. After the intervention, the amount significantly increased $(p<0.001)$ to 91.179 million tons. Also, before the intervention students presumed it would spend an average of 151.60 years to decompose plastics. After the intervention, the figure rose significantly $(p<0.001)$ to 2.161.93 years. These findings are in line with the predictions (Figure 1 and Appendix B). 


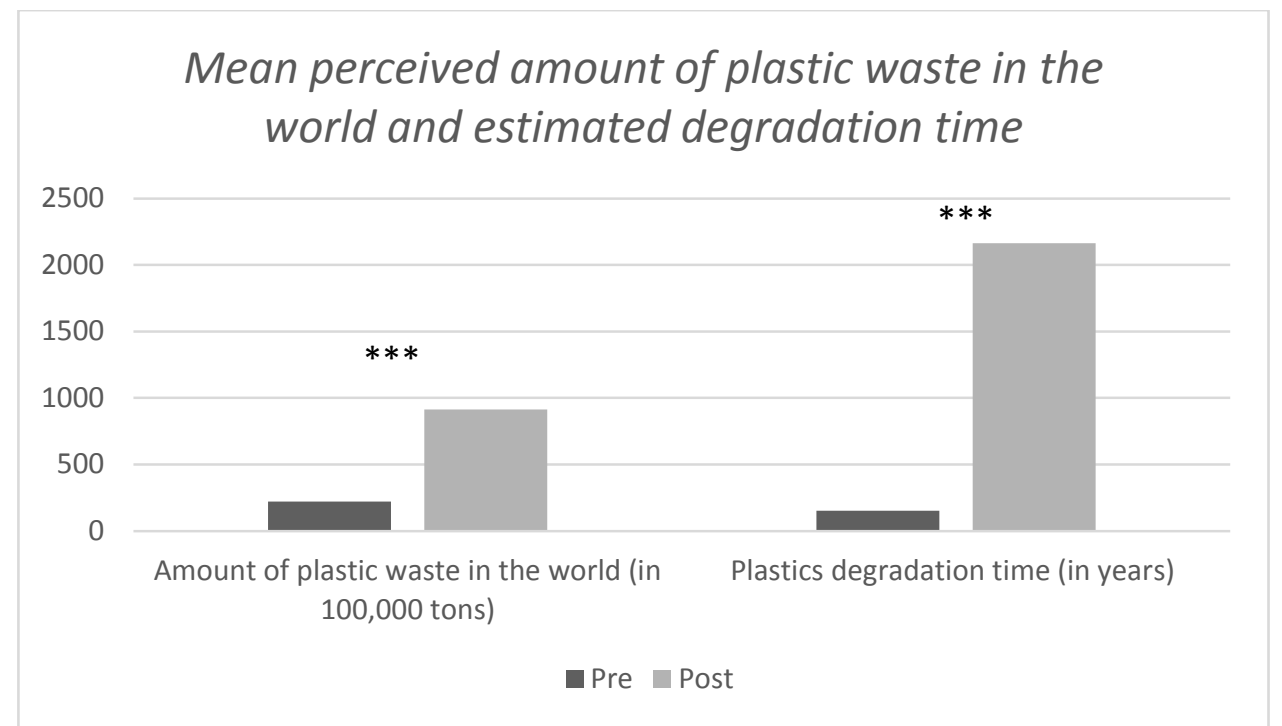

Figure 1. University students' perceived amount of plastic waste in the world (in 100,000 tons) and estimated degradation time (in years) pre- and post-intervention. Note: asterisk signs denote significance level $\left({ }^{* * *} p<0.001\right)$.

Perceived causes of plastic pollution

The pre-intervention response suggested that students perceived all the factors of litter bins insufficiency, too much plastic packaging, and too many people litter in the environment cause plastic pollution. However, after conducting a Friedman test, students perceived the causes differently $\left(\chi^{2}(2)=\right.$ $36.439, \mathrm{p}<0.001)$. Thus, the analysis continued to a series of post hoc Wilcoxon matched-pair tests. The results showed that students perceived too much plastic packaging is the greater cause to plastic pollution compared to too many people litter in the environment $(p<0.05)$ and the insufficiency of litter bins $(p<0.001)$. Students also perceived too many people litter in the environment is the greater cause of plastic pollution compared to the insufficiency of litter bins $(p<0.001)$.

The post-intervention response revealed that the EE intervention influenced students' perception of the cause of plastic pollution, as signified by a set of Wilcoxon sign rank tests. This is evident in the significant improvement of litter bins insufficiency $(p<0.001)$, too much plastic packaging $(p<0.05)$, and too many people litter in the environment $(p<0.001)$. A Friedman test further proved that after the intervention students perceived all the three items equally contribute to plastics pollution. These findings appear as predicted (Figure 2 and Appendix B).

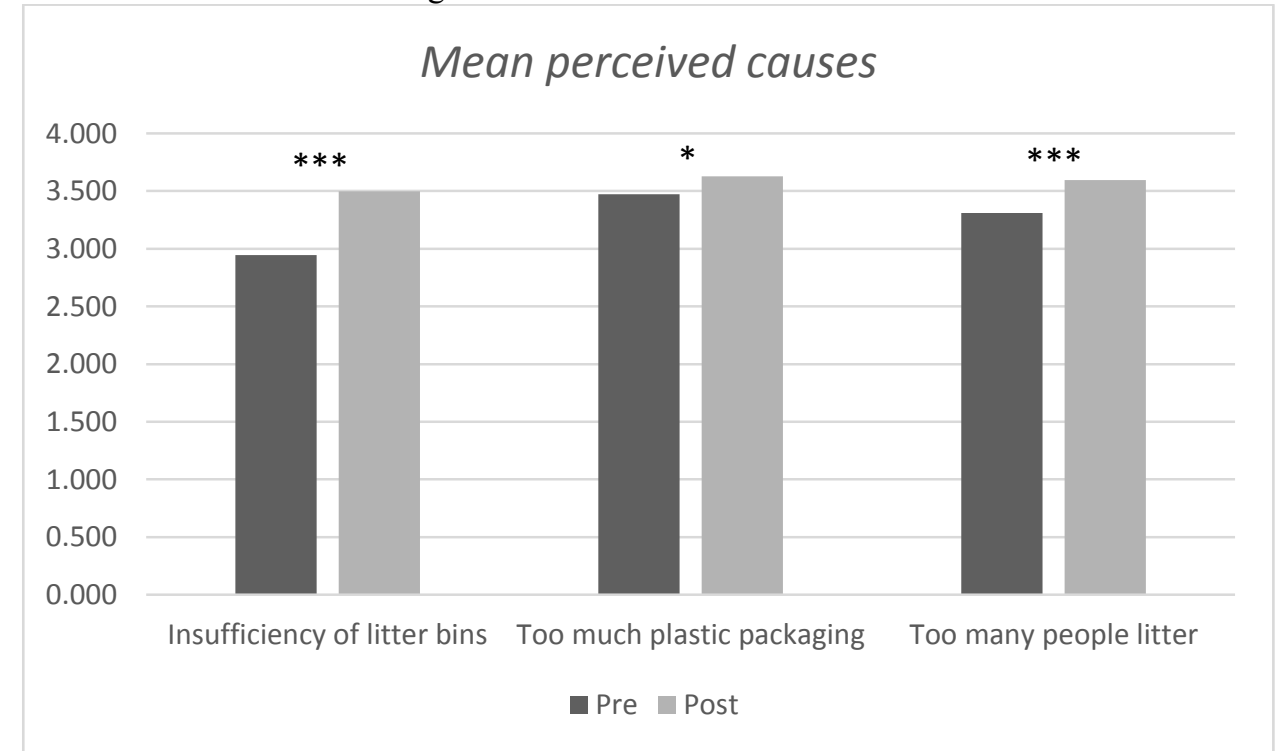

Figure 2. University students' perceived causes of plastic pollution pre- and post-intervention (1-4 scale: strongly disagree - strongly agree). Note: asterisk signs denote significance level ( ${ }^{* *} p<0.001$ and $\left.{ }^{*} p<0.05\right)$. 
Perceived negative impacts of plastics pollution

The pre-intervention response indicates that students perceived plastics pollution potentially damages the marine ecosystem, tourism industry, fishery industry, quality of air, quality of water, quality of soil, humans' organs (i.e., heart, skins, lungs, and brain). Nonetheless, after a Friedman test, students perceived the negative impacts differently $\left(\chi^{2}(9)=40.803, \quad \mathrm{p}<0.001\right)$. Therefore, the examination proceeded to a series of post hoc Wilcoxon matched-pair tests. The results exhibited that students perceived plastics pollution has a higher negative effect on the quality of water compared to fishery industry, quality of soil, tourism industry, and humans' organs (i.e., heart, skins, lungs, and brain) $(p<0.01)$.

Further, a set Wilcoxon sign rank tests uncovered that the $\mathrm{EE}$ intervention improved students' perception of the plastic pollution negative impacts. This is observable in the substantial elevation of perceived negative impacts on the quality of water $(p<0.01)$ and other items $(p<0.001)$. A Friedman test also showed that after the intervention, students perceived plastics pollution equally affects the marine ecosystem, tourism industry, fishery industry, quality of air, quality of water, quality of soil, and humans' organs (i.e., heart, skins, lungs, and brain). These all are in line with the predictions (Figure 3 and Appendix B).

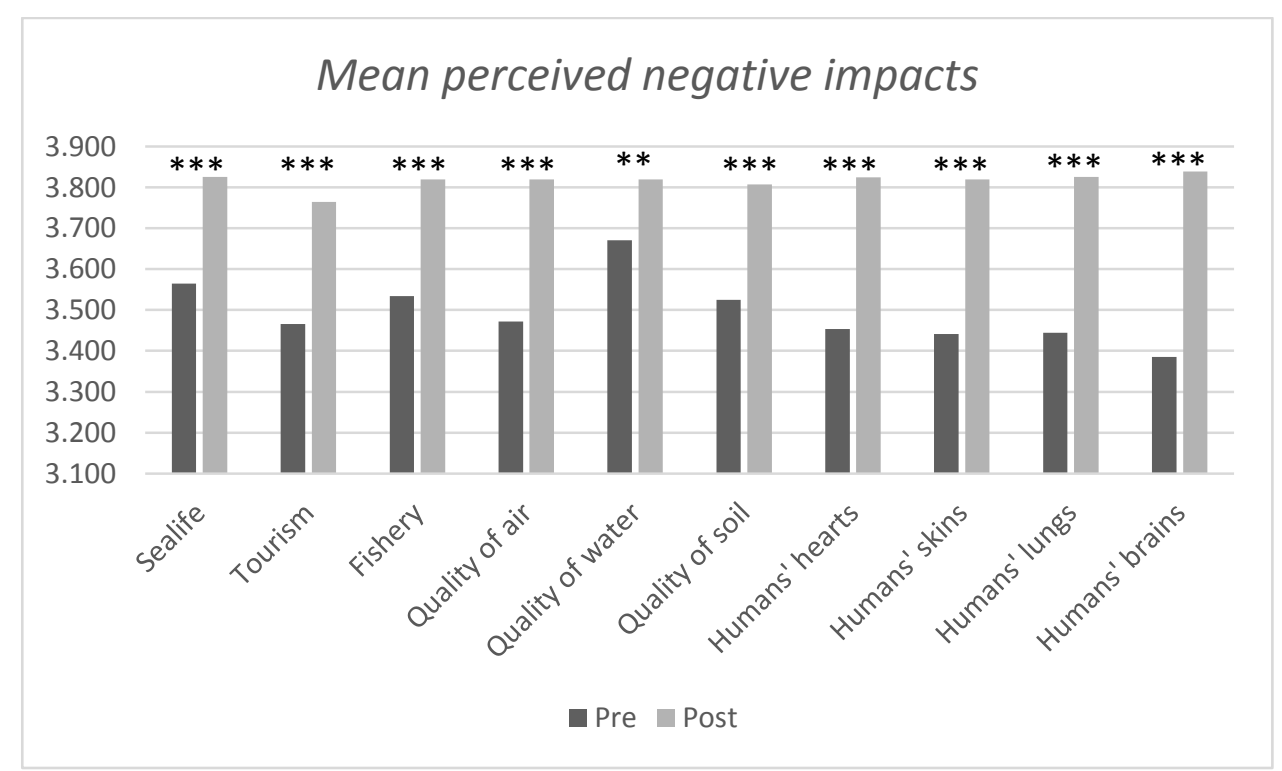

Figure 3. University students' perceived negative impacts of plastic pollution pre- and postintervention (1-4 scale: strongly disagree - strongly agree). Note: asterisk signs denote significance level $\left({ }^{* * *} p<0.001\right.$ and $\left.{ }^{* *} p<0.01\right)$.

\subsection{Attitude}

Before the intervention, students were less willing to spread awareness about plastic pollution. However, after the intervention, a Wilcoxon sign rank test proved that students' willingness to spread awareness about plastic pollution increased significantly $(p<0.05)$. This develops as expected in the prediction (Figure 4 and Appendix B). 


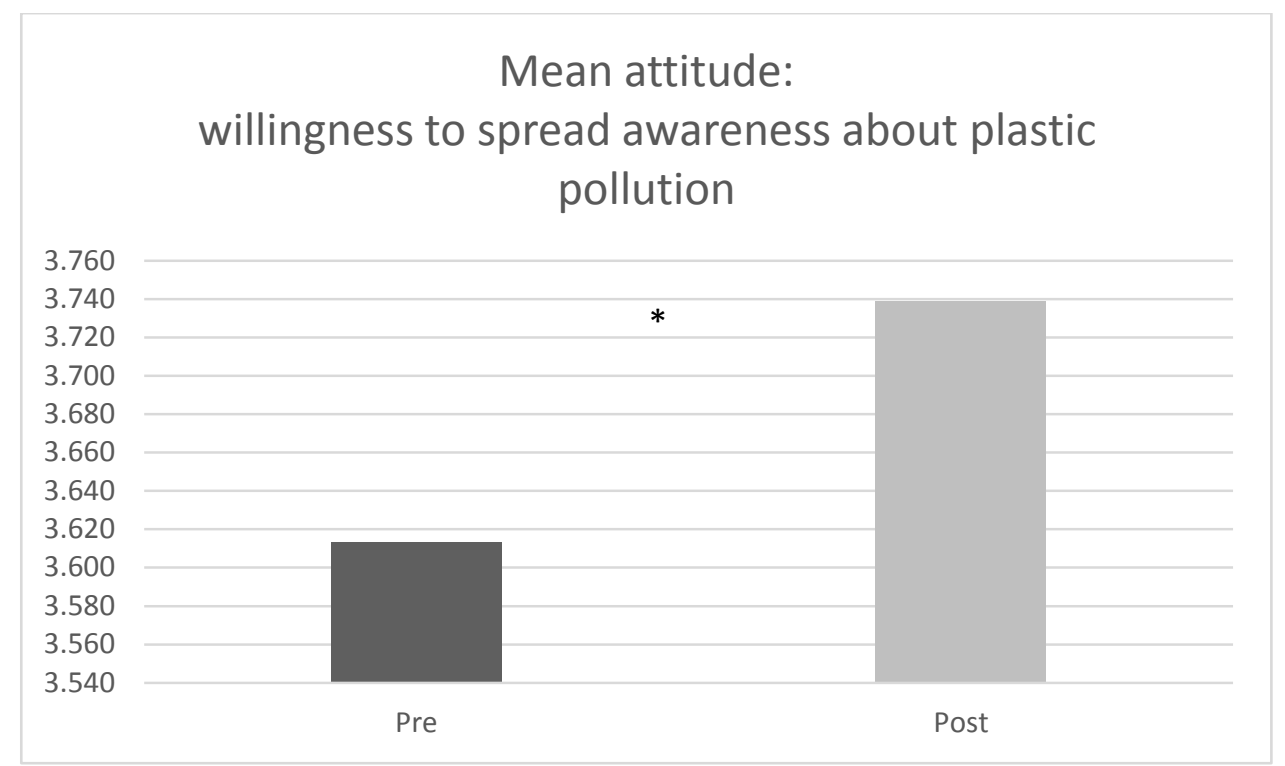

Figure 4. University students' attitude of willingness to spread awareness about plastic pollution pre- and post-intervention (1-4 scale: strongly disagree - strongly agree). Note: asterisk signs denote significance level $\left({ }^{*} p<0.05\right)$.

\subsection{Self-Reported Pro-environmental Behaviour}

Students' response during pre-intervention exhibited that they performed pro-environmental behaviour by bringing on bags for shopping, reducing the usage of single-use plastic bags, and also reducing buying food and beverages that use plastic packaging. Nevertheless, the students performed the pro-environmental behaviour differently as proven by a Friedman test $\left(\chi^{2}(2)=24.863, p<0.001\right)$. Therefore, the inspection advanced to a series of post hoc Wilcoxon matched-pair tests. The analysis found that students implemented pro-environmental behaviour more on reducing the usage of single-use plastic bags contrasted to reducing purchasing food and beverages that use plastic packaging and bringing on bags for shopping $(p<0.001)$.

After the intervention, a series of Wilcoxon sign rank tests verify that there were improvements of students' pro-environmental behaviour. This is exhibited in the significant increase of self-reported pro-environmental behaviour especially in bringing on bags for shopping $(p<0.001)$, reducing the usage of single-use plastic bags $(p<0.01)$, and also reducing buying food and beverages that use plastic packaging $(p<0.001)$. These findings follow the predictions (Figure 6 and Appendix B). 


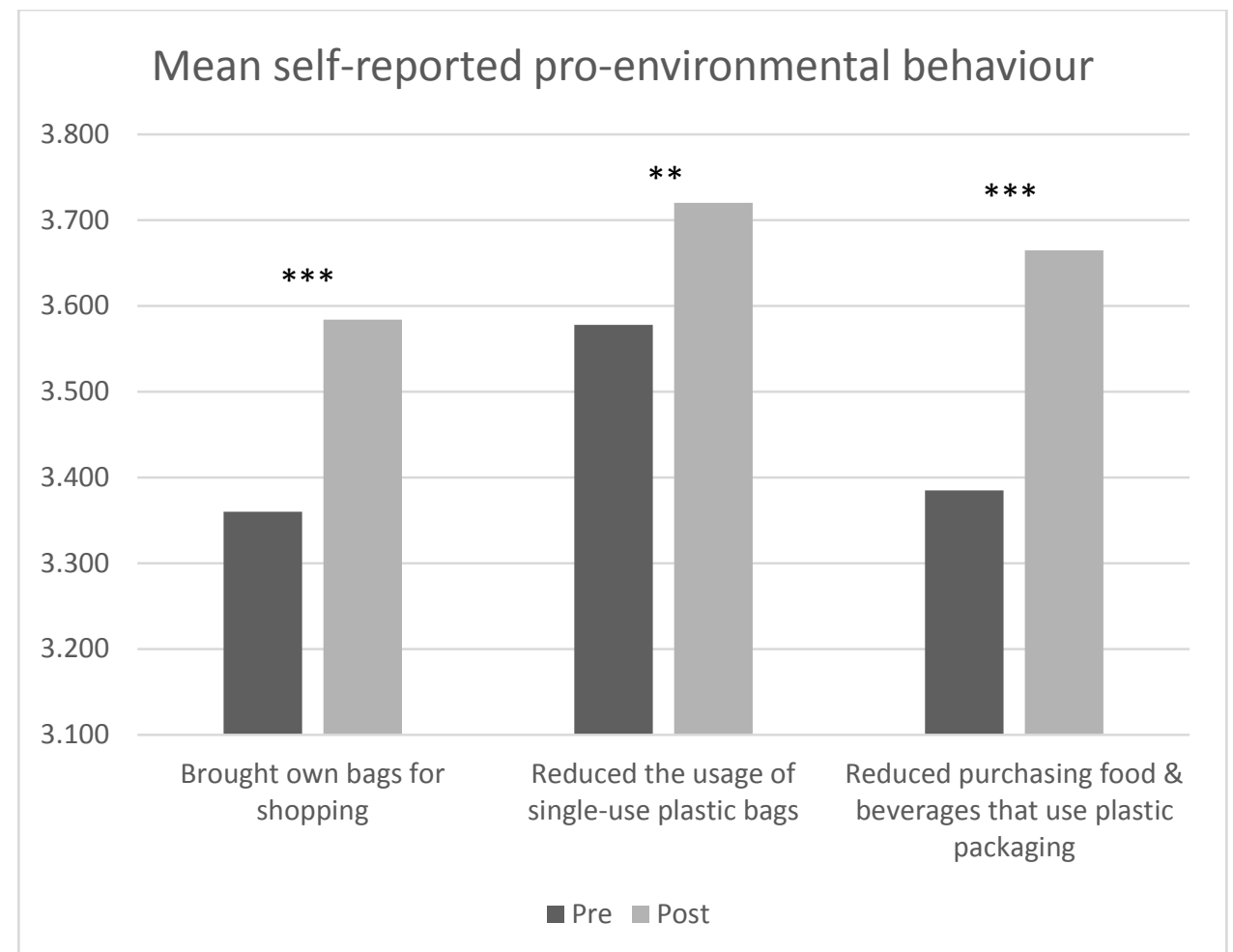

Figure 5. University students' self-reported pro-environmental behaviour pre- and post-intervention (1-4 scale: not at all - a lot). Note: asterisk signs denote significance level ${ }^{* *} p<0.01$ and $\left.{ }^{* * *} p<0.001\right)$.

\subsection{Additional Information}

Regarding with students' intention to join more formal $\mathrm{EE}$ in the future, $95.7 \%$ of them intended to participate, and $4.3 \%$ of them refused to join (Figure 6). When asked about the best media to deliver EE, $71 \%$ of students chose a formal class in a school/university. Meanwhile, in the social media category, students recommended implementing
Instagram (63\%) as opposed to Facebook (30\%), Twitter (30\%), and Snapchat (6\%). In the entertainment and information media group, students' preference fell on YouTube (58\%), then followed by TV (35\%), newspaper $(22 \%)$, blog (17\%), and radio (14\%). Finally, students further proposed a seminar, discussion, and field trip as other media to deliver EE effectively. These statistics are presented in Figure 7.

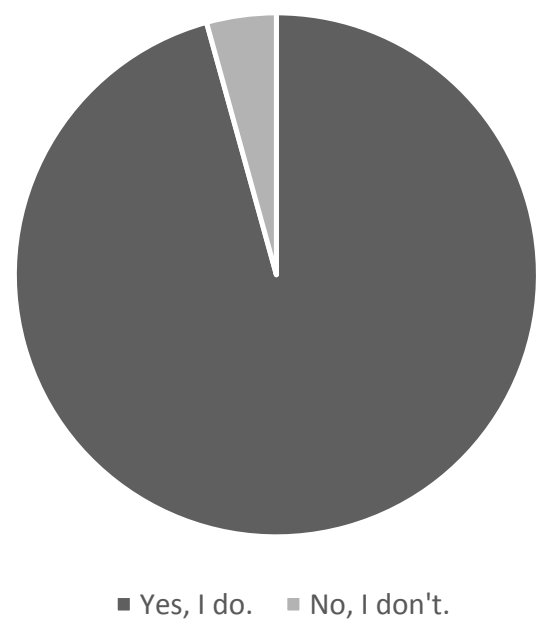

Figure 6. Students' response to the question, "Do you intend to join more formal environmental education in the future?" 


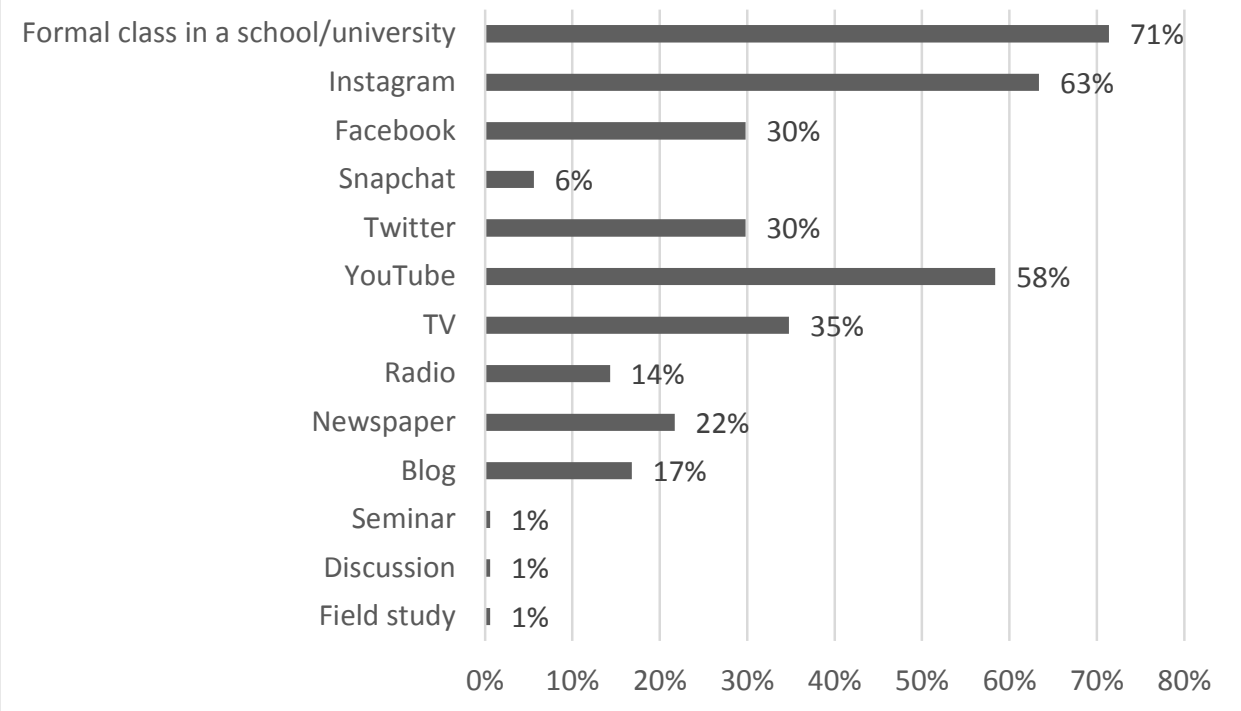

Figure 7. Students' response to the question, "What media do you think are the most effective to deliver environmental education?"

\section{DISCUSSION}

This study aimed to provide EE to students in Universitas Bina Darma in Palembang in an attempt to boost pro-environmental behaviour in reducing plastic consumption. To measure the success or failure of the EE intervention, this study investigated the students' perception, attitudes, and self-reported pro-environmental behaviour concerning plastic consumption and pollution. The response from the pre-intervention survey is favourable. Although the students' perception on the amount of plastic waste in the world was much lower than the actual figure, their perception about plastic degradation time was within the correct range (i.e., between 100 to 1,000 years). The students also were aware of the cause of plastic pollution. Regarding with this finding, students believed excessive usage of plastic packaging in products is the greatest cause of the issue juxtaposed to people littering and the lack of available bins. This indicates that businesses prompt plastic pollution. This result somewhat differs from those of students in England, where they perceived people littering, and businesses are respectively the primary and peripheral reasons for plastic (Hartley, Thompson and Pahl, 2015).

Additionally, the university students also were knowledgeable about the dire impacts of plastic pollution toward marine ecosystem, tourism industry, fishery industry, quality of air, quality of water, quality of soil, and humans' organs (i.e., skins, lungs, hearts, and brains). In this matter, they recognised that plastic pollution negatively affects the quality of water exceedingly compared to other aspects. This occurs maybe because it is common in Indonesia for plastics scattering around beaches, in ditches, and bodies of water. Also, 4 of the most polluted rivers in the world are located in Indonesia. Furthermore, the survey also exhibited that students were willing to spread awareness about plastic pollution. They also had performed pro-environmental behaviour within 7 days before EE intervention, especially in the act of refusing the usage of single-use plastic bags. These encouraging findings appear maybe because $65.2 \%$ of them have attended at least one formal EE class before, and $67.7 \%$ of them live in an urban area.

After participating in the EE intervention, the university students demonstrated a higher understanding of plastic pollution problems. Specifically, their perception of the amount of plastic waste in the world and its degradation time increased significantly. They also considered the insufficiency of litter bins, immoderate use of plastic packaging, and people littering the environment equally promoting plastic pollution. Likewise, their perception of plastic pollution potential damage enhanced substantially. They apprehended that plastic pollution is equally and significantly harmful toward marine ecosystem, tourism industry, fishery industry, quality of air, quality of water, quality of soil, and humans' organs (i.e., skins, lungs, hearts, and brains). Due to all this improvement in perception, students were more informed, and hence they are more willing to spread awareness about plastic pollution to friends and family. Lastly, the EE intervention also boosted the students' proenvironmental behaviour. This is evident in the considerable increase of the act in bringing on bags for shopping, reducing the usage of single-use plastic bags, and also reducing buying food and beverages that use plastic packaging.

All these outcomes proved that the $\mathrm{EE}$ intervention succeeded to foster pro-environmental 
behaviour among university students. The findings are in line with the studies of Sipone et al. (2019), Hartley et al. (2015), and Ma'ruf et al. (2016), but contradictory to Tanu \& Parker (2018) and PrabawaSear (2018). This condition might relate to $\mathrm{EE}$ contents. In this EE intervention, the subject was full education, similar to Sipone et al. (2019), Hartley et al. (2015), and Ma'ruf et al. (2016). The class was unlike in the study of Tanu \& Parker (2018), where the ethos of 'family-togetherness' comes first then followed by EE. The education in this study further offered no rewards to join EE, as in Prabawa-Sear (2018). For Indonesian young consumers context, this research argues that the provision of group identity and remuneration in an EE programme obscures the core of EE contents, which is to educate about complex human-environment interactions. Therefore, formal EE is more desirable. In addition, the success of this programme could be because the students under observation cared about the environments and enjoyed the formal EE class. This was indicated in the post-intervention survey, where more than $95 \%$ of the students intended to participate in other formal $\mathrm{EE}$ in the future, and more than $71 \%$ suggested that a formal class in a school or university is the most effective method to deliver EE.

The implemented EE and results of this study can benefit universities, governments, and nongovernmental bodies for policymaking and other environmental decisions to reduce plastic consumption and pollution. This is even more relevant to Indonesia. Plastic pollution is detrimental for the environment, economy, social, and human health (Xanthos and Walker, 2017), and the country is the second-largest plastics polluter after China (Jambeck et al., 2015; Ritchie and Roser, 2018). University students as young consumers are future educated workers, company leaders, policymakers, and government leaders (Hammami et al., 2017; Parker, Prabawa-Sear and Kustiningsih, 2018). Therefore, equipping them with environmental knowledge and pro-environmental behaviour is probable to create more sustainable future in Indonesia and the world.

Finally, in the theoretical perspective, this investigation offers the following contributions. First, this empirical discussion extends the ethnographic studies among Indonesian students conducted by Prabawa-Sear (2018) and Tanu and Parker (2018). Second, $73 \%$ of EE studies are from developed countries in North America and Europe (VarelaLosada et al., 2016). Thus, this research enriches the EE literature in developing countries, especially concerning plastics consumption and pollution in Indonesia. Third, Ma'ruf et al. (2016) evidenced that knowledge, environmental attitude, and environmental behaviour differ significantly among their respondents in Sumatra, Java, and Bali islands. This occurs because Indonesia is a nation with a vast territory, cultural diversity, and distinct environmental problems encountered by each region (Ma'ruf, Surya and Apriliany, 2016). Therefore, the analysis in Palembang in this study provides new evidence for the EE in Indonesia.

\section{LIMITATIONS AND FURTHER RESEARCH}

Although this study provides satisfactory findings, it carries several limitations. First, the duration between pre- and post-intervention was only within 7 days. During this period, the students' perception was likely to remain high and thus positively influencing the self-reported proenvironmental behaviour. As such, future research should measure students' pro-environmental behaviour during the pre- and post-intervention within longer timeframes (e.g., one month, one semester, or one year). Second, students' environmental knowledge, attitude, and proenvironmental behaviour differ significantly among respondents in Indonesian regions (Ma'ruf, Surya and Apriliany, 2016). The current results from university students in Palembang might be inapplicable for other cities in the country. Ensuing studies might replicate this examination in other universities and cities in Indonesia to corroborate and allow for generalization. Third, the majority of the students under examination have participated in EE before. This might affect their perception and behaviour. Following investigations might divide the samples into two categories: those who have joined EE and those who never have. This will inform them which one needs more intensive education. Lastly, this study presents additional information regarding the most effective media to deliver EE, according to university students. From the survey, other than a formal EE class in a school or university, the majority of respondents further proposed that EE should be delivered through social media Instagram and YouTube. Future studies might implement these media in their investigation and measure their efficacy.

\section{REFERENCES}

1. Auta, H. S., Emenike, C. U. and Fauziah, S. H. (2017) Distribution and importance of microplastics in the marine environment: A review of the sources, fate, effects, and potential solutions', Environment International. Elsevier Ltd, 102, pp. 165-176. doi: 10.1016/j.envint.2017.02.013.

2. Barboza, L. G. A. and Gimenez, B. C. G. (2015) 'Microplastics in the marine environment: Current trends and future perspectives', Marine Pollution Bulletin, 97(1-2), pp. 5-12. doi: 10.1016/j.marpolbul.2015.06.008.

3. da Costa, J. P. et al. (2016) '(Nano)plastics in the environment - Sources, fates and effects', Science of the Total Environment. Elsevier B.V., 
566-567, $\quad$ pp. $\quad 15-26 . \quad$ doi: 10.1016/j.scitotenv.2016.05.041.

4. Ergen, A., Baykan, B. G. and Turan, S. G. (2015) 'Effect of materialism and environmental knowledge on environmental consciousness among high school students: A study conducted in Istanbul province', International Journal of Human Sciences, 12(1), p. 511. doi: 10.14687/ijhs.v12i1.3130.

5. Geyer, R., Jambeck, J. R. and Law, K. L. (2017) 'Production, use, and fate of all plastics ever made', Science Advances, 3(7), pp. 25-29. doi: 10.1126/sciadv.1700782.

6. Gottlieb, D., Vigoda-Gadot, E. and Haim, A. (2013) 'Encouraging ecological behaviors among students by using the ecological footprint as an educational tool: A quasi-experimental design in a public high school in the city of Haifa', Environmental Education Research, 19(6), pp. 844-863. doi: 10.1080/13504622.2013.768602.

7. Hammami, M. B. A. et al. (2017) 'Survey on awareness and attitudes of secondary school students regarding plastic pollution: implications for environmental education and public health in Sharjah city, UAE', Environmental Science and Pollution Research. Environmental Science and Pollution Research, 24(25), pp. 20626-20633. doi: 10.1007/s11356-017-9625-x.

8. Hartley, B. L., Thompson, R. C. and Pahl, S. (2015) 'Marine litter education boosts children's understanding and self-reported actions', Marine Pollution Bulletin. Elsevier Ltd, 90(1-2), pp. 209-217. doi: 10.1016/j.marpolbul.2014.10.049.

9. Hasan, S. N. M. S., Harun, R. and Hock, L. K. (2015) 'Application of Theory of Planned Behavior in Measuring the Behavior to Reduce Plastic Consumption Among Students at Universiti Putra Malaysia, Malaysia', Procedia Environmental Sciences. Elsevier B.V., 30, pp. 195-200. doi: 10.1016/j.proenv.2015.10.035.

10. Jambeck, J. R. et al. (2015) 'Plastic waste inputs from land into the ocean', Science, 347(6223), pp. 764-768. doi: 10.1126/science.1260879.

11. Kiessling, T. et al. (2017) 'Who cares about dirty beaches? Evaluating environmental awareness and action on coastal litter in Chile', Ocean and Coastal Management. Elsevier Ltd, 137, pp. 8295. doi: 10.1016/j.ocecoaman.2016.11.029.

12. Kong, D. et al. (2014) 'Survey on environmental awareness of Shanghai college students', Environmental Science and Pollution Research, 21(23), pp. 13672-13683. doi: 10.1007/s11356014-3221-0.

13. Lebreton, L. C. M. et al. (2017) 'River plastic emissions to the world's oceans', Nature Communications. Nature Publishing Group, 8, pp. 1-10. doi: 10.1038/ncomms15611.

14. Ma'ruf, M., Surya, S. and Apriliany, P. D. (2016) 'Knowledge, Attitudes and Behavior of University Students towards Environmental Issues in Indonesia', Sains Humanika, 8(1-2), pp. 81-88. doi: 10.11113/sh.v8n1-2.836.

15. McCarthy, N. (2020) The Countries Polluting
The Oceans The Most, Statista. Available at: https://www.statista.com/chart/12211/thecountries-polluting-the-oceans-the-most/ (Accessed: 20 July 2020).

16. Ogunola, O. S., Onada, O. A. and Falaye, A. E. (2018) 'Mitigation measures to avert the impacts of plastics and microplastics in the marine environment (a review)', Environmental Science and Pollution Research. Environmental Science and Pollution Research, 25(10), pp. 9293-9310. doi: 10.1007/s11356-018-1499-z.

17. Ohtomo, S. and Ohnuma, S. (2014) Psychological interventional approach for reduce resource consumption: Reducing plastic bag usage at supermarkets, Resources, Conservation and Recycling. doi: 10.1016/j.resconrec.2013.12.014.

18. Parker, L. (2018) 'Environmentalism and education for sustainability in Indonesia', Indonesia and the Malay World. Taylor \& Francis, 46(136), pp. 235-240. doi: 10.1080/13639811.2018.1519994.

19. Parker, L., Prabawa-Sear, K. and Kustiningsih, $W$. (2018) 'How young people in Indonesia see themselves as environmentalists: Identity, behaviour, perceptions and responsibility', Indonesia and the Malay World. Taylor \& Francis, 46(136), pp. 263-282. doi: 10.1080/13639811.2018.1496630.

20. Prabawa-Sear, K. (2018) 'Winning beats learning: Environmental education in Indonesian senior high schools', Indonesia and the Malay World. Taylor \& Francis, 46(136), pp. 283-302. doi: 10.1080/13639811.2018.1496631.

21. Raman Sharma, V. K. and Sharma, M. (2014) 'Plastics: Issues Challenges and Remediation', International Journal of Waste Resources, 04(01), pp. 1-6. doi: 10.4172/22525211.1000134.

22. Ritchie, H. and Roser, M. (2018) Plastic Pollution, Our World in Data. Available at: https://ourworldindata.org/plasticpollution\#citation (Accessed: 20 July 2020).

23. Rivers, N., Shenstone-Harris, S. and Young, N. (2017) 'Using nudges to reduce waste? The case of Toronto's plastic bag levy', Journal of Environmental Management. Elsevier Ltd, 188, pp. 153-162. doi: 10.1016/j.jenvman.2016.12.009.

24. Sipone, S. et al. (2019) 'Learning about sustainable mobility in primary schools from a playful perspective: A focus group approach', Sustainability (Switzerland), 11(8). doi: 10.3390/sul1082387.

25. Tanu, D. and Parker, L. (2018) 'Fun, "family", and friends: Developing pro-environmental behaviour among high school students in Indonesia', Indonesia and the Malay World. Taylor \& Francis, 46(136), pp. 303-324. doi: 10.1080/13639811.2018.1518015.

26. Varela-Losada, M. et al. (2016) 'Going to action? A literature review on educational proposals in formal Environmental Education', Environmental Education Research, 22(3), pp. 
390-421. doi: 10.1080/13504622.2015.1101751.

27. Vethaak, A. D. and Leslie, H. A. (2016) 'Plastic Debris is a Human Health Issue', Environmental Science and Technology, 50(13), pp. 6825-6826. doi: 10.1021/acs.est.6b02569.

28. Wang, J. et al. (2016) 'The behaviors of microplastics in the marine environment', Marine Environmental Research. Elsevier Ltd, 113, $\quad$ pp. 7-17. doi: 10.1016/j.marenvres.2015.10.014.

29. Xanthos, D. and Walker, T. R. (2017) 'International policies to reduce plastic marine pollution from single-use plastics (plastic bags and microbeads): A review', Marine Pollution Bulletin. Elsevier Ltd, 118(1-2), pp. 17-26. doi: 10.1016/j.marpolbul.2017.02.048. 